\title{
The Real Term Premium in a Stationary Economy with Segmented Asset Markets
}

YiLi Chien and Junsang Lee

\begin{abstract}
This article proposes a general equilibrium model to explain the positive and sizable term premia implied by the data. The authors introduce a slow mean-reverting process of consumption growth and a segmented asset-market mechanism with heterogeneous trading technologies into an otherwise standard heterogeneous agent general equilibrium model. First, the slow mean-reverting consumption growth process implies that the expected consumption growth rate is only slightly countercyclical and the process can exhibit near-zero first-order autocorrelation, as observed in the data. This slight countercyclicality suggests that long-term bonds are risky, and hence the term premia should be positive. Second, the segmented asset-market mechanism amplifies the magnitude of the term premia because aggregate risk is highly concentrated in a small fraction of marginal traders who demand high compensation for taking risk. For sensitivity analysis, the role of each assumption is further investigated by removing each factor one at a time. (JEL G11, G12, E30)
\end{abstract}

Federal Reserve Bank of St. Louis Review, Second Quarter 2019, 101(2), pp. 115-34.

https://doi.org/10.20955/r.101.115-34

\section{INTRODUCTION}

The positive and sizable term premia observed in the data have been hard to reconcile using a standard structural macroeconomic model. Backus, Gregory, and Zin (1989) demonstrate the failure of a standard model in accounting for the sign and the magnitude of real bond risk premia. Campbell (1986), Donaldson, Johnsen, and Mehra (1990), and den Haan (1995) also experience the same difficulty with standard macroeconomic models. ${ }^{1}$

Although equilibrium models are difficult to work with and have limited success, it is still important to try to understand the fundamental mechanisms behind positive and sizable term premia. For macroeconomists, the disconnect between the observed term premia in the data and what a standard structural macroeconomic model predicts is often referred to as the "term premium puzzle." The issue is also important to central bankers. As pointed out by

YiLi Chien is an economist and research officer at the Federal Reserve Bank of St. Louis. Jungsang Lee, the corresponding author, is an associate professor at Sungkyunkwan University, Seoul, Korea.

( ) 2019, Federal Reserve Bank of St. Louis. The views expressed in this article are those of the author(s) and do not necessarily reflect the views of the Federal Reserve System, the Board of Governors, or the regional Federal Reserve Banks. Articles may be reprinted, reproduced, published, distributed, displayed, and transmitted in their entirety if copyright notice, author name(s), and full citation are included. Abstracts, synopses, and other derivative works may be made only with prior written permission of the Federal Reserve Bank of St. Louis. 


\section{Chien and Lee}

Wright (2011), the term premia represent the relationship between the short rate, which is controlled by central banks, and the long rate, which relates more deeply to real economic activities. Hence, understanding the term premia helps central bankers evaluate the effectiveness of monetary policy and the mechanism behind its effects on the real economy. Finally, for investors, it is of utmost importance to understand term premia-to hedge against interest rate risk.

A standard macroeconomic model with the pricing kernel or the stochastic discount factor derived from a utility maximization problem generally has great difficulty matching the slope and the level of the term structure. Campbell (1986) shows that the term premium depends on the nature of the consumption growth process. If the consumption growth process is positively autocorrelated, then the expected future growth rate falls and bond prices rise in a recession. The long-term bond then becomes a good hedge, and hence the term premium is negative. On the other hand, if the consumption growth rate is negatively autocorrelated, then the model predicts a positive term premium since the long-term bond becomes risky because of its procyclical pricing. This intuition together with near-zero autocorrelation of consumption growth, that is, a random walk in empirical studies, implies that the term premium should be close to zero when the pricing kernel is derived from a standard macroeconomic model.

In addition, it is also well known that the pricing kernel of a standard model, which relies purely on the expected aggregate consumption growth rate, is not volatile enough to deliver a high market price of risk. Therefore, the standard model not only fails to match the sign of the term premium but also fails to generate the correct magnitude of the term premium.

In this article, we assume that the aggregate consumption process is trend stationary with a long memory process, which shows near zero but slightly negative autocorrelation of the consumption process. This consumption process alone generates positive term premia but with very small magnitude. This process is not easily statistically distinguished from a difference-stationary process such as the random walk. This view is supported by Christiano and Eichenbaum (1990,) who argue that no clear statistical evidence exits to support either a trend-stationary or a difference-stationary process of aggregate consumption. More specifically, we consider a slow trend-reverting aggregate consumption process in our model economy and hence the level of consumption can be well above or below its long-run trend for an extended period. With this process, when a bad shock is realized, the expected growth rate of consumption is only slightly higher because of its slow mean-reverting property. Therefore, the expected growth rate of consumption is only slightly countercyclical and the autocorrelation of consumption growth between two consecutive periods could be very close to zero but slightly negative (only - 0.02 in our calibrated model), which is consistent with the randomwalk-like consumption process in the data.

Following Chien, Cole, and Lustig (2011), there is a segmented asset-market mechanism in our model. Specifically, the model features a large fraction of households who do not participate in the equity market and hence do not bear any aggregate risk. There is, however, a small fraction of households who do participate in the equity market and hence bear a great amount of aggregate risk, which in this article results in a high market price of risk. In equi- 
librium, those households demand high risk compensation. As a result, high risk premia are obtained not only in equities but also reflected onto long-term bonds. Therefore, the segmented market mechanism amplifies the size and the magnitude of the term premia.

Our calibrated model considers not only the segmented asset-market mechanism but also the asymmetric bond positions of U.S. households. The data on U.S. households show that a large fraction of households carry long-term mortgage loans but save in short-term risk-free assets, such as checking or savings accounts. In other words, these households essentially borrow in long-term bonds by using housing as a collateral and save in short-term bonds. In our calibrated model, we also evaluate the extent to which this asymmetric bond position of households matters for term premia quantitatively.

The assumptions in our model are built with solid support from empirical evidence. The first assumption, of a mean-reverting consumption growth process, is prevalent in the macroeconomics literature. The growth of aggregate variables, such as output or consumption, is often decomposed into trend components and cyclical components (business cycles). Such a decomposition is consistent with the mean-reverting assumption. The second assumption, of a segmented market mechanism, is firmly grounded in empirical evidence from the household finance literature. The evidence shows that most households do not purchase most of the assets available to them (Guiso and Sodini, 2012). In fact, the composition of household asset holdings varies greatly across households, even in a developed country such as the United States. Only 50 percent of U.S. households participate in the equity market, according to the 2010 Survey of Consumer Finance (SCF hereafter) data. Moreover, even among the participants in the equity market, many investors still hold low-risk portfolios and do not adjust

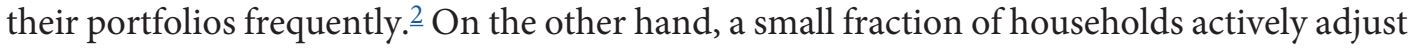
their portfolios and earn a higher return by taking more aggregate risk. The SCF data also show that a large fraction of households carry mortgage loans and save in short-term safe assets. These households effectively have a long position in short-term bonds and a short position in long-term bonds. As the data also show, wealthier households, a relatively small fraction of all households, tend to hold a higher fraction of long-term bonds in their portfolios.

Only a handful of structural models in the literature are able to deliver an average upwardsloping nominal and/or real yield curve. Many of them modify household preferences into various forms in the standard macroeconomic model. Piazzesi and Schneider (2007) demonstrate that the nominal yield curve can be upward sloping even with a flat or downward-sloping real yield curve since a low-frequency negative correlation between consumption growth and the inflation rate causes inflation risk. They assume a recursive preference, and hence agents are very willing to substitute consumption over time even though they are risk averse. The recursive preference plays a critical role in the low-frequency correlation mattering for the current price. Bansal and Shaliastovich (2013) also generate a positive nominal term premium with inflation risks and recursive preferences. Rudebusch and Swanson (2012) further extend the endowment economy model to a production economy general equilibrium model. By introducing inflation ambiguity into a representative agent model, Ulrich (2013) explains the upward-sloping nominal yield curve with a log utility function. Our work is complementary to the existing papers discussed above since we focus on the real term premia rather than 


\section{Chien and Lee}

the nominal premia. Wachter (2006) uses a habit-persistence model to explain both the positive real and nominal bond premia. To maintain the consumption level, investors tend to sell long-term bonds during recessions and vice versa during expansions. Namely, the demand for long-term bonds is procyclical, which makes the bond price procyclical and hence the longterm bond itself a risky asset. Rudebusch and Swanson (2012) find that the habit-formation mechanism in Wachter (2006) fails to generate a sizable term premia without distorting the behavior of other macroeconomics variables.

Our benchmark model generates a high and volatile equity premium with a 7.26 percent mean and a 15.63 percent standard deviation, as well as a low and stable risk-free return with a 0.95 mean and a 1.45 percent standard deviation-estimates quite close to those in the assetpricing literature. Most importantly, our quantitative result also predicts a high real term premium: 1.92 percent for 30-year zero-coupon bonds. This article delivers a reasonable term premium result, with a risk aversion coefficient of 4 . For the sensitivity analysis, we further investigate the role of our assumptions by removing each factor one by one.

Our main contribution to the literature is to provide a simple and intuitive story that can reconcile the puzzling disconnect between asset prices, equity and term premia in particular, and aggregate macroeconomic variables. The model in this article integrates the empirical facts of heterogeneous portfolios across households, as found in the household finance literature, and a mean-reverting aggregate consumption process, as found in the macroeconomics literature, to explain the real term-premia puzzle. Our model successfully delivers a positive sign for and significant magnitude of the real term premia. Specifically, we demonstrate the importance of the household portfolio heterogeneity documented in the macro-finance literature, while the majority of asset-pricing models rely on a representative agent framework with modifications to preferences.

\section{THE MODEL}

We consider an endowment economy in which households sequentially trade assets and consume. Two features distinguish our model from the standard model. First, our endowment (consumption) growth follows a slow mean-reverting process. After the realization of a bad endowment shock, the expected consumption growth rate edges up only slightly because of the trend-reverting property, which makes the autocorrelation of the consumption growth process slightly negative but very close to zero. Hence, our shock process is consistent with the empirical fact that consumption growth is well approximated by the random walk.

The second key feature of our model is that it exhibits ex-ante heterogeneity in the trading technologies. The trading technologies are modeled on the menu of assets, specifically by exogenously restricting the portfolios a household can trade and hold. The goal of these restrictions is to capture the observed portfolio behavior of most households. In our calibrated model, this form of ex-ante heterogeneity delivers a high market price of risk and hence helps to deliver sizable term premia. 


\subsection{The Environment}

There is a unit measure of households subject to both aggregate endowment growth risks and idiosyncratic income shocks. Households are ex-ante identical except for the trading technologies that they are endowed with. Ex post, these households differ in terms of their idiosyncratic income-shock realizations. All households face the same stochastic process for idiosyncratic income shocks, and all households start with the same present value of wealth.

In the model, time is discrete, infinite, and indexed by $t=0,1,2, \ldots$ The first period, $t=0$, is a planning period in which all trading takes place. We assume constant average growth of the endowment process and a transitory shock that makes the actual level of aggregate consumption deviate from its long-term trend. More specifically, let $m_{t}$ be the percentage deviation of aggregate endowment from the growth trend. Then, the total endowment in period $t$, denoted by $Y_{t}$, is

$$
\ln Y_{t}=t \ln \bar{g}+m_{t}
$$

where $\bar{g}$ is the average growth rate of the endowment. The output growth process is therefore affected by the evolution of $m_{t}$, which is assumed to follow an AR(1) process:

$$
m_{t+1}=\rho m_{t}+\varepsilon_{t+1}, \varepsilon_{t+1} \sim N\left(0, \sigma_{\varepsilon}^{2}\right) .
$$

With this specification of the endowment shock process, the growth rate of output, denoted by $g_{t+1} \equiv \frac{Y_{t+1}}{Y_{t}}$, is therefore given by

$$
\ln \frac{Y_{t+1}}{Y_{t}} \equiv \ln g_{t+1}=\ln \bar{g}+(\rho-1) m_{t}+\varepsilon_{t+1}
$$

If $\rho$ is 1 , then the endowment process follows a random walk with drift, a difference-stationary process. If $\rho$ is less than 1 but close to 1 , then the endowment slowly reverts to trend, a trendstationary process (a long-memory property). As mentioned in the Introduction, there is no clear evidence in favor of either a trend-stationary or difference-stationary process for macroeconomic variables, such as consumption or output. Our model follows the view of a trendstationary endowment process with long memory. Hence, the value of $\rho$ is set to 0.95 in the calibration.

Let $z^{t}$ denote the history of aggregate states up to period $t$, and hence let $Y_{t}\left(z^{t}\right)$ denote the aggregate endowment is period $t$. In addition, aggregate endowment each period is divided into two parts: diversifiable income and nondiversifiable income. Claims to diversifiable income can be traded in financial markets, while claims to nondiversifiable income cannot. We assume a constant share of nondiversifiable income, denoted by $\gamma \in(0,1)$. The nondiversifiable component is subject to idiosyncratic stochastic shocks, denoted by $\eta_{t}$. Nondiversifiable household income is denoted by $\gamma Y_{t}\left(z^{t}\right) \eta_{t}$.

Similarly, let $\eta^{t}$ denote the history of idiosyncratic shocks up to period $t$. In addition, we use $\pi\left(z^{t}, \eta^{t}\right)$ to denote the unconditional probability of state $\left(z^{t}, \eta^{t}\right)$ being realized. The idio- 


\section{Chien and Lee}

syncratic shock events are governed by a first-order Markov process, and their probabilities are assumed independent between $z$ shocks and $\eta$ shocks:

$$
\pi\left(z^{t+1}, \eta^{t+1} \mid z^{t}, \eta^{t}\right)=\pi\left(z_{t+1} \mid z^{t}\right) \pi\left(\eta_{t+1} \mid \eta^{t}\right) .
$$

Since we can appeal to the law of large numbers, $\pi\left(\eta^{t}\right)$ also denotes the fraction of agents in state $z^{t}$ that have drawn the history $\eta^{t}$. We introduce some additional notation: $z^{t+1}>z^{t}$ or $\eta^{t+1}>\eta^{t}$ means that the left-hand-side node is a successor node to the right-hand-side node. We denote by $\left\{z^{\tau}>z^{t}\right\}$ the set of successor aggregate histories for $z^{t}$, including those many periods in the future; ditto for $\left\{\eta^{\tau}>\eta^{t}\right\}$. When we use $\geq$, we include the current nodes $z^{t}$ or $\eta^{t}$ in the set.

All households live for infinite periods and rank a stream of consumption according to the following criterion:

$$
U(\{c\})=\sum_{t \geq 1,\left(z^{t}, \eta^{t}\right)}^{\infty} \beta^{t} \frac{1}{1-\alpha} c_{t}\left(z^{t}, \eta^{t}\right)^{1-\alpha} \pi\left(z^{t}, \eta^{t}\right),
$$

where $\alpha$ denotes the coefficient of relative risk aversion, $\beta$ denotes the time discount factor, and $c_{t}\left(z^{t}, \eta^{t}\right)$ denotes household consumption in state $\left(z^{t}, \eta^{t}\right)$.

In this economy, there are four type of assets available: state-contingent claims on aggregate shocks, a long-term bond (consol) with a constant stream of payments, risky equities, and one-period risk-free bonds. Note that the market is incomplete in our environment since there is no state-contingent claims available for idiosyncratic shocks. Equity is assumed to be a leveraged aggregate output process, with dividend growth determined by

$$
\Delta \ln D_{t+1}=E_{t}\left(\Delta \ln Y_{t+1}\right)+\phi\left[\Delta \ln Y_{t+1}-E_{t}\left(\Delta \ln Y_{t+1}\right)\right],
$$

where $\phi$ is the leverage ratio, which is assumed constant over time. Finally, we denote the value of total equity by $V_{t}\left(z^{t}\right)$. The gross returns of leveraged equity, or $R_{t, t-1}^{e}\left(z^{t}\right)$, are given by

$$
R_{t, t-1}^{e}\left(z^{t}\right)=\frac{D_{t}\left(z^{t}\right)+V_{t}\left(z^{t}\right)}{V_{t-1}\left(z^{t-1}\right)} .
$$

\subsection{Heterogeneity in Trading Technologies}

To match the size of the term premium, we introduce the segmented market mechanism, in particular portfolio heterogeneity at the household level. As mentioned in the Introduction, heterogeneity in portfolio choices is widely supported by the data. As we demonstrate later, the concentration of a large portion of aggregate risk in a relatively small fraction of households amplifies the price of risk in the calibrated model. Without such a mechanism, the model fails to match the size of the term premium quantitatively. To capture such portfolio heterogeneity, we adopt the approach by Chien, Cole, and Lustig (2011), which exogenously imposes different restrictions on investors' portfolio choices. These restrictions apply to the menu of assets that households can trade as well as to the composition of households' portfolios. 
There are two classes of investors in terms of their asset-trading technologies: Mertonian traders and non-Mertonian traders. Mertonian traders face no restrictions on their portfolio choices and hence a menu of tradable assets. Specifically, they are capable of trading a complete set of contingent claims on the aggregate endowment. They optimally adjust their portfolio choices in response to changes in the set of investment opportunities. Therefore, they act as market arbitrageurs and price aggregate risk in our model.

Non-Mertonian traders face restrictions on their portfolio choices. Specifically, their portfolio composition is restricted to be constant over time. There are two types of nonMertonian traders: The first type, non-Mertonian equity investors, can trade equities, riskfree bonds, and long-term bonds but not state-contingent claims on aggregate shocks. The second type, nonparticipants, do not hold equity but invest only in risk-free bonds and console bonds. Even though the portfolio composition of non-Mertonian traders is exogenously given, they can still choose how much to save and consume.

Non-Mertonian investors deviate from the optimal portfolio choice in two dimensions: First, they cannot change the share of equities, long-term bonds, or short-term bonds in their portfolios in response to changes in the market price of risk, which indicates missed market timing. Second, their portfolio share in each asset might deviate from the optimal share on average, implying that their average exposure to aggregate risk might not be optimal. We denote the measure of different types of households by $\mu_{j}$, where $j \in\{m e, e t, n p\}$ represents Mertonian investors, non-Mertonian equity investors, and non-Mertonian nonparticipants, respectively.

\subsection{The Household's Problem}

2.3.1 Budget Constraints of Mertonian Traders. Consider a Mertonian trader entering the period with net financial wealth $a_{t}\left(z^{t}, \eta^{t-1}\right)$ given the event history $\left(z^{t}, \eta^{t-1}\right)$. Note that net financial wealth is not spanned by the realization of idiosyncratic shocks, $\eta_{t}$, since there are no contingent claims on idiosyncratic shocks. At the end of the period, Mertonian traders buy shares of equities $s_{t}\left(z^{t}, \eta^{t}\right)$, one-period risk-free bonds $b_{t}\left(z^{t}, \eta^{t}\right)$, long-term consol bonds $b_{t}^{c}\left(z^{t}, \eta^{t}\right)$, and state-contingent claims, $\hat{a}_{t}\left(z^{t}, \eta^{t-1}\right)$ in financial markets, and consumption $c_{t}\left(z^{t}, \eta^{t}\right)$ in the goods markets is subject to the following one-period budget constraint:

$$
\begin{aligned}
& s_{t}\left(z^{t}, \eta^{t}\right) V_{t}\left(z^{t}\right)+b_{t}\left(z^{t}, \eta^{t}\right)+b_{t}^{c}\left(z^{t}, \eta^{t}\right)+\sum_{z_{t+1}} Q\left(z^{t+1} \mid z^{t}\right) \hat{a}_{t+1}\left(z^{t+1}, \eta^{t}\right)+c_{t}\left(z^{t}, \eta^{t}\right) \\
& \leq a_{t}\left(z^{t}, \eta^{t-1}\right)+\gamma Y_{t}\left(z^{t}\right) \eta^{t}, \text { for all } z^{t}, \eta^{t},
\end{aligned}
$$

where $Q\left(z^{t+1} \mid z^{t}\right)$ denotes the state-contingent price of a unit contingent claim to the consumption good in aggregate state $z^{t+1}$ acquired in aggregate state $z^{t}$. The agent's net financial wealth, $a_{t}\left(z^{t}, \eta^{t-1}\right)$, in state $\left(z^{t}, \eta^{t}\right)$ is given by the payoff from the agent's portfolio last period:

$$
\begin{aligned}
& a_{t}\left(z_{t}, \eta^{t-1}\right)=s_{t-1}\left(z^{t-1}, \eta^{t-1}\right)\left[D_{t}\left(z^{t}\right)+V_{t}\left(z^{t}\right)\right]+R_{t, t-1}^{f}\left(z^{t-1}\right) b_{t-1}\left(z^{t-1}, \eta^{t-1}\right) \\
& +R_{t, t-1}^{c}\left(z^{t}\right) b_{t-1}^{c}\left(z^{t-1}, \eta^{t-1}\right)+\hat{a}_{t}\left(z^{t}, \eta^{t-1}\right)
\end{aligned}
$$




\section{Chien and Lee}

where $R_{t, t-1}^{c}\left(z^{t}\right)$ and $R_{t, t-1}^{f}\left(z^{t-1}\right)$ denote the return of a long-term consol bond and a one-period risk-free bond in period $t$, respectively. Note that the total equity share of this economy, $s_{t}\left(z^{t}, \eta^{t}\right)$, is normalized to 1 .

2.3.1 Budget Constraints of Non-Mertonian Traders. The non-Mertonian traders have no access to state-contingent claims on aggregate shocks and are restricted to fixed portfolio weights among the equity, short-term risk-free bonds, and long-term consol bonds. At the end of period $t$, the households buy equity shares, one-period risk-free bonds, and long-term consol bonds, subject to a fixed target portfolio equity share and long-bond share, denoted by $\bar{\omega}^{e}$ and $\bar{\omega}^{c}$, respectively. As a result, in addition to equations (4) and (5), their constraints also include a portfolio restriction,

$$
\begin{aligned}
& \bar{\omega}^{e}=\frac{s_{t}\left(z^{t}, \eta^{t}\right) V_{t}\left(z^{t}\right)}{s_{t}\left(z^{t}, \eta^{t}\right) V_{t}\left(z^{t}\right)+b_{t}\left(z^{t}, \eta^{t}\right)+b_{t}^{c}\left(z^{t}, \eta^{t}\right)} \\
& \bar{\omega}^{c}=\frac{b_{t}^{c}\left(z^{t}, \eta^{t}\right)}{s_{t}\left(z^{t}, \eta^{t}\right) V_{t}\left(z^{t}\right)+b_{t}\left(z^{t}, \eta^{t}\right)+b_{t}^{c}\left(z^{t}, \eta^{t}\right)},
\end{aligned}
$$

and no access to state-contingent claims

$$
\hat{a}_{t}\left(z^{t}, \eta^{t-1}\right)=0 \text { for all } z^{t} \text { and } \eta^{t-1} .
$$

The portfolio share of short-term bonds is therefore $1-\bar{\omega}^{e}-\bar{\omega}^{c}$.

Alternatively, we can simplify the budget constraint of non-Mertonian traders as follows:

$$
\hat{s}_{t}\left(z^{t}, \eta^{t}\right)+c\left(z^{t}, \eta^{t}\right) \leq R_{t, t-1}^{p}\left(z^{t}\right) \hat{s}_{t-1}\left(z^{t-1}, \eta^{t-1}\right)+\gamma Y_{t}\left(z^{t}\right) \eta_{t},
$$

where $\hat{s}_{t}$ denotes the asset holdings at the end of period $t . R_{t, t-1}^{p}\left(z^{t}\right)$ represents the gross return on the fixed portfolio imposed on the non-Mertonian traders and is given by

$$
R_{t, t-1}^{p}\left(z^{t}, \eta^{t}\right)=\bar{\omega}^{e} R_{t, t-1}^{e}\left(z^{t}\right)+\bar{\omega}^{c} R_{t, t-1}^{c}\left(z^{t}\right)+\left(1-\bar{\omega}^{e}-\bar{\omega}^{c}\right) R_{t, t-1}^{f}\left(z^{t}\right)
$$

In the case of nonparticipants, $\bar{\omega}^{e}$ is zero.

Finally, all households are subject to nonnegative net wealth constraints, given by $a_{t}\left(z^{t}, \eta^{t-1}\right) \geq 0$ for Mertonian and $\hat{s}_{t}\left(z^{t}, \eta^{t}\right) \geq 0$ for non-Mertonian traders. The details of the household problem and its associated optimal conditions are provided in Appendix A.1.

\subsection{The Competitive Equilibrium}

The competitive equilibrium for this economy is defined in the standard way. It consists of a consumption allocation, allocations of state-contingent claims, one-period risk-free bonds, long-term consol bonds, and equity choices as well as a list of prices such that (i) given these prices, households' assets and consumption choices maximize the households' expected utility subject to the budget constraints, the solvency constraints, and the constraints on their portfolio choices and (ii) all asset markets clear. 


\section{QUANTITATIVE RESULTS}

This section performs a quantitative exercise of our model. The next two subsections explain how we calibrate idiosyncratic shocks and aggregate shocks as well as the pool of traders in the benchmark case. Next, we briefly describe the real Treasury yields observed in the data. Finally, we report our benchmark asset-pricing quantitative results, especially the size of the real term premia, in Subsection 3.4.

\subsection{Calibration}

The calibration of aggregate shocks is critical to our results. The aggregate endowment process is assumed to have a constant growth trend and an innovation term that makes the realization of output deviate from its trend:

$$
\ln Y_{t}=t \ln \bar{g}+m_{t}
$$

where $\bar{g}$ is the average growth rate of the endowment and the deviation from trend is captured by a variable $m$, which is assumed to follow the $\mathrm{AR}(1)$ process

$$
m_{t+1}=\rho m_{t}+\varepsilon_{t+1}, \varepsilon_{t+1} \sim N\left(0, \sigma_{\varepsilon}^{2}\right) .
$$

We use a two-state Markov process to approximate the independent and identically distributed innovation $\varepsilon_{t}$. More specifically, since expansions occur more often than recessions, the probability of a good innovation shock is set to 27.4 percent, as in Alvarez and Jermann (2001). However, the expected endowment growth rate in each period depends on how far the current consumption level has deviated from its trend, which depends on the whole past history of innovation shocks. In computation, we therefore have to keep track of one extra state variable, $m$, in order to compute the conditional expected growth rate.

Our model operates at an annual frequency. The average aggregate consumption growth rate $\bar{g}$ is set to 1.8 percent with a standard deviation of 3.15 percent. Given that the aggregate consumption growth data are well approximated by the random walk in the short run, the persistency of $m$ has to be high. We set $\rho=0.95$, which makes the consumption growth autocorrelation of -0.02 sufficiently close to zero.

We also consider a two-state first-order Markov chain for idiosyncratic shocks. The first state is low and the second state is high. Following Alvarez and Jermann (2001) and Storesletten, Telmer, and Yaron (2004), we calibrate the shock process by two moments: the standard deviation of idiosyncratic shocks and the first-order autocorrelation of the shocks, except we eliminate the countercyclical variation in idiosyncratic risk. The Markov process for the log of the nondiversified income share, $\ln \eta$, has a standard deviation of 0.71 and an autocorrelation of 0.89 . The transition probability is denoted by

$$
\pi\left(\eta^{\prime} \mid \eta\right)=\left[\begin{array}{cc}
0.945 & 0.055 \\
0.055 & 0.945
\end{array}\right] .
$$




\section{Chien and Lee}

The two states of the idiosyncratic shock, for which the mean is normalized to 1, are $\eta_{L}=0.3894$ and $\eta_{H}=1.6106$.

All households have the identical constant relative risk aversion preference. In our calibration, there are strong incentives for household to save because of idiosyncratic shocks in an incomplete-market environment, which causes the risk-free rate to be lower than the reciprocal of the preference discount factor $\beta$, even in a growing economy As a result, we set the time discount factor to $\beta=0.95$ to match the low risk-free rate in our benchmark model. The risk-aversion rate $\alpha$ is set to 4 to produce a high risk premium in our benchmark calibration.

Following Mendoza, Quadrini, and Rios-Rull (2009), the fraction of nondiversifiable output is set to 88.75 percent. As shown in Section 2, equity in our model is simply a leveraged claim to the diversifiable income process. Following Abel (1999) and Bansal and Yaron (2004), the leverage ratio parameter is set to 3 .

\subsection{The Composition of Traders}

In the model, 50 percent of U.S. households are stock market nonparticipants, as in the 2010 SCF data. The remaining 50 percent do hold equities, and we divide them into nonMertonian equity traders and Mertonian traders as discussed. To match the high risk premia, a small fraction of Mertonian traders must absorb a large amount of aggregate risk. We therefore set the fraction of Mertonian traders to 5 percent for our benchmark economy. The remaining fraction of households, 45 percent, are classified as non-Mertonian equity traders, who can own constant portfolio shares in short risk-free bonds, long-term risky bonds, and equities.

In addition to the equity market participation rate, the portfolio shares of non-Mertonian traders are also important parameters. Again, we use the 2010 SCF data to calibrate the portfolio share of non-Mertonian equity traders and non-participants in our model, which account for 45 percent and 50 percent of the population, respectively.

To identify the portfolio choice of the non-Mertonian equity traders, we must first sort by equity position the 50 percent of households in the data that hold equities and then compute the average equity share excluding the top 5 percent of equity holders. The average computed equity share is 21.1 percent, which we use as the equity share of non-Mertonian equity traders in the benchmark case. This calibration reflects the observations both from the data and from our model that more sophisticated households tend to hold larger amounts of equities.

\subsection{The Real Yield Curve in the Data}

Using the constructed international data on zero-coupon yields, Wright (2011) demonstrates that nominal term premia are estimated to be positive among 10 industrialized countries. However, we do not observe the real term premium directly from the data and the positive nominal term premia do not necessarily imply positive real term premia, because of inflation risk. Strong empirical evidence supporting the real term premia comes from the real Treasury yield. The average real Treasury yields for 5-year, 7-year, and 10-years maturities are listed in Table 1 for different sample periods. For 2003 to 2007, the average 5-year, 7-year, and 10-year real Treasury yields are 1.646 percent, 1.871 percent, and 2.061 percent, respectively, which indicates a positive real term premium. The real yield data decrease after 2009 as the sample 
Table 1

The Real Treasury Yield

\begin{tabular}{lccc} 
Period/Maturity & 5-year & 7-year & 10-year \\
\hline 2003 to 2007 & 1.646 & 1.871 & 2.061 \\
\hline 2003 to 2009 & 1.513 & 1.757 & 1.962 \\
\hline 2003 to 2011 & 1.160 & 1.452 & 1.715 \\
\hline 2003 to 2013 & 0.772 & 1.082 & 1.367 \\
\hline 2003 to 2015 & 0.658 & 0.968 & 1.226 \\
\hline
\end{tabular}

SOURCE: U.S. Department of Treasury; https://www.treasury.gov/resource-center/data-chart-center/interest-rates/Pages/TextView.aspx?data=realyield.

Table 2

Quantitative Results

\begin{tabular}{|c|c|c|c|c|c|}
\hline Case & Benchmark & No mortgage & No NME & No HTT & RA economy \\
\hline Mertonian & $5 \%$ & $5 \%$ & $50 \%$ & $100 \%$ & $100 \%$ \\
\hline Non-Mertonian equity & $45 \%$ & $45 \%$ & $0 \%$ & $0 \%$ & $0 \%$ \\
\hline Nonparticipant & $50 \%$ & $50 \%$ & $50 \%$ & $0 \%$ & $0 \%$ \\
\hline$\omega_{e t}$ & $(0.211,-0.195)$ & $(0.211,0)$ & NA & NA & NA \\
\hline$\omega_{n p}$ & $(0,-0.537)$ & $(0,0)$ & NA & NA & NA \\
\hline$E\left(R^{z c 30}-R^{f}\right)$ & 1.924 & 1.713 & 0.678 & 0.427 & 0.532 \\
\hline$\frac{\sigma(Q)}{E(Q)}$ & 0.475 & 0.464 & 0.204 & 0.135 & 0.133 \\
\hline $\operatorname{Std}\left(\frac{\sigma_{t}(Q)}{E_{t}(Q)}\right)$ & 9.766 & 9.494 & 1.077 & 0.033 & 0.000 \\
\hline$E\left(R^{e}-R^{f}\right)$ & 7.262 & 6.937 & 2.602 & 1.697 & 1.741 \\
\hline$\frac{\sigma\left(R^{e}-R^{f}\right)}{E\left(R^{e}-R^{f}\right)}$ & 0.465 & 0.455 & 0.204 & 0.135 & 0.132 \\
\hline$E\left(R^{f}\right)$ & 0.949 & 1.206 & 3.485 & 3.923 & 11.714 \\
\hline$\sigma\left(R^{f}\right)$ & 1.449 & 1.296 & 1.326 & 1.365 & 2.049 \\
\hline
\end{tabular}

NOTE: Parameter settings: risk aversion rate, $\gamma=4$; discount factor, $\beta=0.95$; nondiversifiable share of income, $\gamma=0.885$; and leverage ratio: $\phi=3$. NME, non-Mertonian equity trader. $\mathrm{HTT}$, heterogeneous trading technologies. RA, representative agent. The simulation results are generated by an economy with 3,000 agents and 10,000 periods. 
Figure 1

The Average Real Yield Curve in the Benchmark Case, the Zero-Coupon Bond

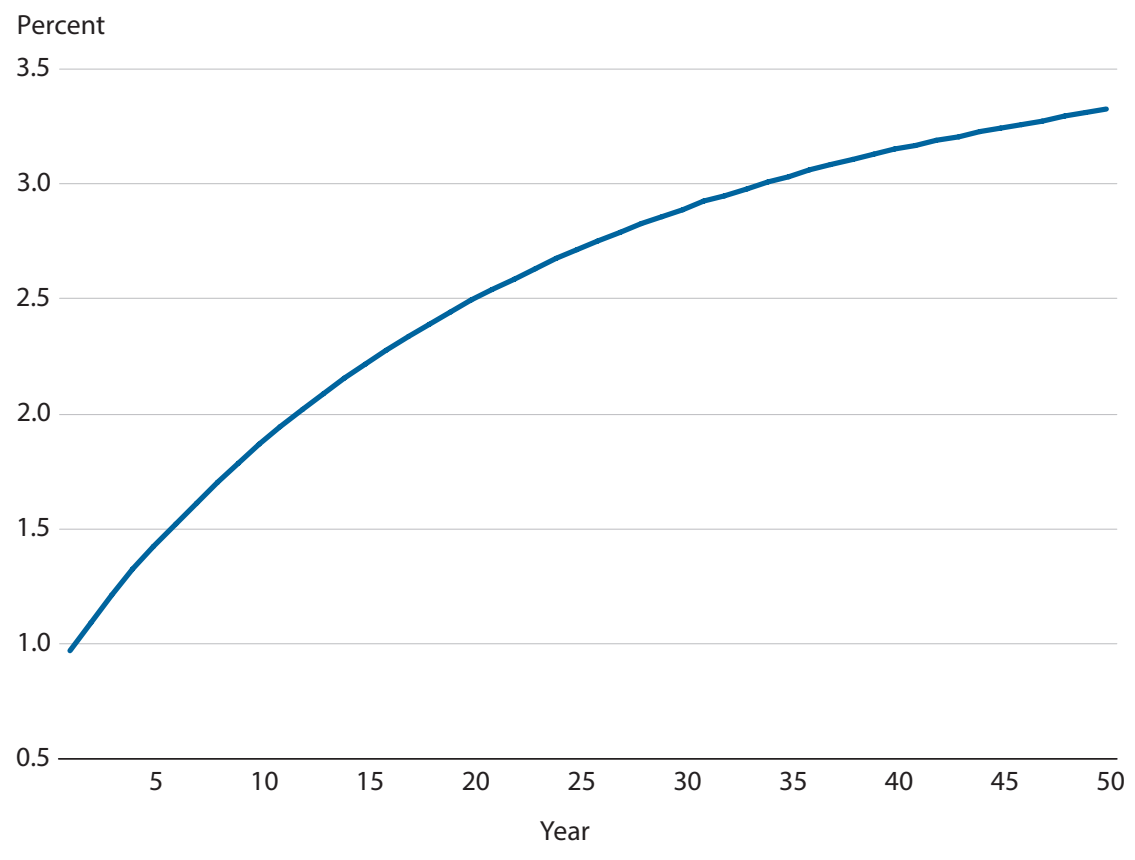

periods become longer. This is because the short-term real rate becomes negative. However, the sizable positive real term premia implied by the data should remain robust to the different sample periods.

\subsection{Benchmark Results}

The benchmark asset-pricing results are shown in the "Benchmark" column in Table 2. First, we report the real term premia of our model, defined as the average yield difference between a 30-year and a 1-year zero-coupon bond, denoted by $E\left(R^{z c 30}-R^{f}\right)$. In addition, Table 2 also includes the market price of risk, $\sigma(Q) / E(Q)$; the conditional standard deviation of the market price of risk, $\operatorname{st}(\sigma(Q) / E(Q))$; the equity premium $E\left(R^{e}-R^{f}\right)$, the Sharpe ratio on equity returns $E\left(R^{e}-R^{f}\right) / \sigma\left(R^{e}-R^{f}\right)$; the average risk-free rate $E\left(R^{f}\right)$; and the standard deviation of the risk-free rate $\sigma\left(R^{f}\right)$.

As explained earlier, the long bond is risky because its price tends to fall during recessions, which is simply a result of higher expected growth after recessions. In our benchmark case, the average term premium of a 30 -year zero-coupon bond is 1.924 percent. To illustrate the upward-sloping real yield curve, Figure 1 plots the yield curve of zero-coupon bonds.

In addition, our benchmark economy produces a high and volatile market price of risk as well as a low and stable risk-free rate. These asset-pricing statistics are hard to match in standard macroeconomic model, as indicated by Mehra and Prescott (1985). In the benchmark 
case of Table 2, the market price of risk is high, 0.475 , and volatile, with a standard deviation of 9.766 percent. The equity premium reaches 7.262 percent, and the Sharpe ratio on equity is 0.465 . The average risk-free rate is low at 0.949 percent, and its volatility is only 1.449 percent. Hence, our calibrated model is capable of producing reasonable asset-pricing results. In our model, the success of matching high-risk premia and low risk-free rates relies on two key frictions. The first friction is the incomplete market with respect to idiosyncratic risk. It is well known that incomplete-market models can produce reasonable risk-free rates in a growing economy. The second friction, which is limited participation combined with a relatively small fraction of Mertonian traders, produces a high equity premium by concentrating aggregate risk on Mertonian traders.

Our results show the mechanism of our model is able to deliver positive term premia of sufficient magnitude. This success comes from imposing the trend-reverting consumption process and heterogeneous portfolio choices into an otherwise standard macroeconomic model. In the next section, we explore the relative importance of these assumptions.

\section{TREND REVERTING VERSUS A RANDOM WALK}

The trend-reverting endowment process is important to our results. If the endowment growth process truly follows a random walk, then long-bond returns do not necessarily fall during recessions and hence the standard model might fail to generate even a positive bond premium. In this subsection, we demonstrate this point analytically in the representative agent economy.

Given the assumption of our shock process, the following lemma describes the expression for the term premia as well as its property in a representative agent economy.

Lemma 1. The unconditional expectation of the term premium for a $k$-period zero-coupon bond is

$$
E\left[r_{t}^{k}-r_{t}^{1}\right]=\left[1-\frac{1}{k} \frac{1-\rho^{2 k}}{1-\rho^{2}}\right] \frac{\alpha^{2} \sigma_{\varepsilon}^{2}}{2} .
$$

In addition, the term premium, $E\left[r_{t}^{k}-r_{t}^{l}\right]$ is increasing in $k$ given $0<\rho<1$.

Proof. Please refer to Appendix Section A.2.

With $0<\rho<1$ in the representative agent economy, Lemma 1 not only shows a positive term premium but also shows that the term premium is increasing in $k$, an indication of an upward-sloping real yield curve. However, if $\rho=1$, the random-walk case, the average term premium shown in equation (6) becomes zero and independent of $k$. The independence implies a flat yield curve.

This result is not surprising in the sense that the autocorrelation of the consumption growth rate is negative when $0<\rho<1$ and becomes zero when $\rho=1$. This can be seen clearly from the fact that $\operatorname{cov}\left(\ln g_{t+1}, \ln g_{t}\right)=-\left(\frac{1-\rho}{1+\rho}\right) \sigma^{2}<0$ if $\rho<1$. However, if $\rho$ is sufficiently close to 1 , then the consumption growth correlation is close to zero, which is not far from what we observe in the data. 
The quantitative results of a representative agent economy with a trend-reverting process are reported in the "RA economy" column of Table 2 . The term premium is positive, as shown in this subsection. However, the term premium is not sizable, at only 0.487 percent, because of the absence of a high market price of risk, which drops significantly to only 0.133 from 0.475 in our benchmark economy.

\section{INSPECTION OF THE MECHANISM}

In our benchmark economy, two features quantitatively contribute to the sizable real term premia: the heterogeneous trading technologies and the mortgage effects. In this section, we decompose the contribution of each feature by removing each one from our benchmark economy.

\subsection{No Mortgage Effects}

Part of the real bond risk premia could be from the asymmetric bond portfolio holdings across households, which is motivated by the heterogeneous amounts of mortgages held across households. Here, we simply shut down this channel by assuming that both nonparticipants and non-Mertonian equity holders do not have a position on long-term bonds. The "No mortgage" column of Table 2 reports the results. We find that this asymmetric bond portfolio channel has minor effects on the market price of risk and equity risk premia. The market price of risk decreases slightly, from 0.475 to 0.464 , as does the standard deviation of the market price of risk, from 9.766 percent to 9.494 percent. The equity premium decreases 32.5 basis points to 6.937 percent. The risk-free rate increases to 1.206 percent from 0.949 percent, and the standard deviation of the risk-free rate decreases to 1.296 percent from 1.449 percent.

As for the impact on the real term premia, the 30 -year term premium drops by 21 basis points. This exercise revels that the asymmetric portfolios in terms of bond maturity play only a minor role in increasing bond risk premia.

\subsection{No Non-Mertonian Equity Traders}

In this subsection, we highlight the importance of distinguishing between Mertonian traders and non-Mertonian equity traders. Both types of traders hold equity, and hence it is not easy to distinguish between them in the data. In fact, most of the work in the segmented market literature does not consider the possibility of different types of equity market participants. We remove the differences between these two types of equity market participants and assume all are Mertonian traders. The assumption of a trend-reverting process for the endowment growth rate remains unchanged. The results are reported in the "No NME" column of Table 2.

With half of total households now Mertonian traders and able to absorb the residual risk created by nonparticipants, aggregate risk is not concentrated enough quantitatively. The market price of risk and the term premium are greatly reduced. Quantitatively, the market price of risk drops significantly to 0.204 from 0.475 . The equity premium is only 2.602 percent, 
and the term premium for a 30-year zero-coupon bond drops significantly, to only 0.678 percent.

This sensitivity analysis suggests that a high market price of risk is essential to our results. The large fraction of nonparticipants and few equity market participants not only helps to match the high and volatile equity risk premia, but also goes a long way to increasing the real bond risk premia.

\subsection{No Heterogeneous Trading Technologies}

In this subsection, we remove totally the heterogeneous trading technologies assumed in the model. All households are now Mertonian traders and face no restriction on their portfolio choices. The results are reported in the "No HTT" column of Table 2. With the force of heterogeneous risk loading completely absent, the model acts similar to a Bewley-type model and exhibits low risk premia. The market price of risk, the equity premium, and the term premium are all small and close to those in a representative agent model. $\underline{3}$

\section{CONCLUSION}

We find that a slow mean-reverting shock process of consumption growth and a segmented asset-market mechanism with a heterogeneous trading technology can quantitatively account for the positive and sizable term premium for bonds as suggested by the data. The slow mean-reverting consumption process explains the positive term premia, although the size of the premia is still very small quantitatively. Our quantitative exercise shows that with this slight modification of the aggregate shock process, the long-term bond is risky because the risk-free rate is slightly countercyclical, even in the representative agent model. The segmented market mechanism with a heterogeneous trading technology and an asymmetric bond position across households can amplify the size and magnitude of the term premia while raising the market price of aggregate risk.

We think our model is the first step in resolving the inconsistency between theoretical macroeconomic models and the empirical asset-pricing findings of the yield curve, with no modification of preferences. There are two obvious directions for future research that can improve the model. For the asset-pricing literature, one can enrich the model by additionally introducing a long-term consumption growth shock in order to match more properties of real bond premia found in the empirical literature. For macroeconomics, our mechanism does not rely on the modification of preferences, and the behavior of asset pricing is pinned down by a relatively small set of marginal investors in a segmented market mechanism. Therefore, the consumption and saving behaviors of most households stay close to those in a standard macroeconomic model. It is more likely that our results extend to a general equilibrium production economy without comprising dynamics of other macroeconomic variables. 


\section{APPENDIX}

\section{A.1 THE TIME-ZERO TRADING HOUSEHOLD PROBLEM}

This appendix describes an equivalent version of this economy in which all households trade at time zero. The time-zero price of a claim that pays one unit of consumption in node $z^{t}$ can be constructed recursively from the one-period-ahead Arrow prices:

$$
P\left(z^{t}\right) \pi\left(z^{t}\right)=Q\left(z_{t} \mid z^{t-1}\right) Q\left(z_{t-1} \mid z^{t-2}\right) \ldots Q\left(z_{1} \mid z^{0}\right) Q\left(z_{0}\right) .
$$

The net financial wealth position of any trader given the trader's history can be stated as

$$
-a_{t}\left(z^{t}, \eta^{t}\right)=\sum_{s \geq t} \sum_{\left.z^{s}, \eta^{s}\right) \geq\left(z^{t}, \eta^{t}\right)} \tilde{P}\left(z^{s}, \eta^{s}\right)\left[\gamma Y\left(z^{s}\right) \eta_{s}-c\left(z^{s}, \eta^{s}\right)\right]
$$

where $\tilde{P}\left(z^{t}, \eta^{t}\right)=\pi\left(z^{t}, \eta^{t}\right) P\left(z^{t}\right)$. From the above equation, we are able to write the household problem in the form of a time-zero trading problem, as shown in the next subsection.

\section{A.1.1 The Household Optimization Problem}

Following Chien, Cole, and Lustig (2011), we state the household problem in this ArrowDebreu economy.

We start with the Mertonian traders' problem in the home country. There are two constraints. Let $\chi$ denote the multiplier on the present value budget constraint and $\varphi\left(z^{t}, \eta^{t}\right)$ denote the multiplier on debt constraints. The saddle-point problem of a Mertonian trader can be stated as follows:

$$
\begin{aligned}
& L=\min _{\{\chi, v, \varphi\}} \max _{\{c\}} \sum_{t=1}^{\infty} \beta^{t} \sum_{z^{t}, \eta^{t}} \frac{1}{1-\alpha} c\left(z^{t}, \eta^{t}\right)^{1-\alpha} \pi\left(z^{t}, \eta^{t}\right) \\
&+ \chi\left\{\sum_{t=1}^{\infty} \sum_{\left(z^{t}, \eta^{t}\right)} \tilde{P}\left(z^{t}, \eta^{t}\right)\left[\gamma Y\left(z^{t}\right) \eta_{t}-c\left(z^{t}, \eta^{t}\right)\right]+a_{0}\left(z^{0}\right)\right\} \\
&-\sum_{t=1}^{\infty} \sum_{\left(z^{t}, \eta^{t}\right)} \varphi_{t}\left(z^{t}, \eta^{t}\right)\left\{\sum_{s \geq t} \sum_{s\left(z^{s}, \eta^{s}\right) \succeq\left(z^{t}, \eta^{t}\right)} \tilde{P}\left(z^{s}, \eta^{s}\right)\left[\gamma Y\left(z^{t}\right) \eta_{s}-c\left(z^{s}, \eta^{s}\right)\right]\right\} .
\end{aligned}
$$

The first-order condition with respect to consumption is given by

$$
\beta^{t} c\left(z^{t}, \eta^{t}\right)^{-\alpha}=\zeta\left(z^{t}, \eta^{t}\right) P\left(z^{t}\right) \text { for all }\left(z^{t}, \eta^{t}\right)
$$

where $\zeta\left(z^{t}, \eta^{t}\right)$ is defined recursively as

$$
\zeta_{t}\left(z^{t}, \eta^{t}\right)=\zeta_{t-1}\left(z^{t-1}, \eta^{t-1}\right)-\varphi_{t}\left(z^{t}, \eta^{t}\right)
$$

with initial $\zeta_{0}=\chi$. It is easy to show that this is a standard convex constraint maximization problem. Therefore, the first-order conditions are necessary and sufficient.

Non-Mertonian traders face additional restrictions on their portfolio choices. Let $v_{t}\left(z^{t}, \eta^{t}\right)$ denote the multiplier on portfolio restrictions. Given the same definition of other multipliers 
as in the active-trader problem, the saddle-point problem of a nonparticipant trader whose assets at the end of the period are $\hat{a}_{t-1}\left(z^{t-1}, \eta^{t-1}\right)$ can be stated as

$$
\begin{aligned}
& L=\min _{\{\chi, v, \varphi\}} \max _{\{c, \hat{s}\}} \sum_{t=1}^{\infty} \beta^{t} \sum_{z^{t}, \eta^{t}} \frac{1}{1-\alpha} c_{t}\left(z^{t}, \eta^{t}\right)^{1-\alpha} \pi\left(z^{t}, \eta^{t}\right) \\
& \chi\left\{\sum_{t=1}^{\infty} \sum_{\left(z^{t}, \eta^{t}\right)} \tilde{P}\left(z^{t}, \eta^{t}\right)\left[\gamma Y\left(z^{t}\right) \eta_{t}-c\left(z^{t}, \eta^{t}\right)\right]+a_{0}\left(z^{0}\right)\right\} \\
&+\sum_{t=1}^{\infty} \sum_{\left(z^{t}, \eta^{t}\right)} v_{t}\left(z^{t}, \eta^{t}\right)\left\{\begin{array}{c}
\Sigma_{s \geq t} \Sigma_{\left(z^{s}, \eta^{s}\right) \succeq\left(z^{t}, \eta^{t}\right)} \tilde{P}\left(z^{s}, \eta^{s}\right)\left[\gamma Y\left(z^{s}\right) \eta_{s}-c\left(z^{s}, \eta^{s}\right)\right] \\
+\tilde{P}\left(z^{t}, \eta^{t}\right) R_{t, t-1}^{p}\left(z^{t}\right) \hat{s}_{t-1}\left(z^{t-1}, \eta^{t-1}\right)
\end{array}\right\} \\
&-\sum_{t=1}^{\infty} \sum_{\left(z^{t}, \eta^{t}\right)} \varphi_{t}\left(z^{t}, \eta^{t}\right)\left\{\sum_{s \geq t} \sum_{s\left(z^{s}, \eta^{s}\right) \succeq\left(z^{t}, \eta^{t}\right)} \tilde{P}\left(z^{s}, \eta^{s}\right)\left[\gamma Y\left(z^{s}\right) \eta_{s}-c\left(z^{s}, \eta^{s}\right)\right]\right\} .
\end{aligned}
$$

The first-order condition with respect to consumption is given by

$$
\beta^{t} c\left(z^{t}, \eta^{t}\right)^{-\alpha}=\zeta\left(z^{t}, \eta^{t}\right) P\left(z^{t}\right) \text { for all }\left(z^{t}, \eta^{t}\right)
$$

where $\zeta\left(z^{t}, \eta^{t}\right)$ is defined as

$$
\zeta_{t}\left(z^{t}, \eta^{t}\right)=\zeta_{t-1}\left(z^{t-1}, \eta^{t-1}\right)+v_{t}\left(z^{t}, \eta^{t}\right)-\varphi_{t}\left(z^{t}, \eta^{t}\right)
$$

Therefore, the first-order condition with respect to consumption is independent of trading restrictions. The first-order condition with respect to total asset holdings at the end of period $t-1, \hat{s}_{t-1}\left(z^{t-1}, \eta^{t-1}\right)$ is

$$
\sum_{z^{t}, \eta^{t}} R_{t, t-1}^{p}\left(z^{t}\right) v_{t}\left(z^{t}, \eta^{t}\right) P\left(z^{t}\right) \pi\left(z^{t}, \eta^{t}\right)=0 \text { for all } z^{t}, \eta^{t} .
$$

This condition varies according to the different trading restrictions.

\section{A.1.2 Stochastic Discount Factor}

By summing the first-order condition with respect to consumption, equation (7), across all domestic households at period $t$, we obtain the consumption sharing rule as follows:

$$
\frac{c\left(z^{t}, \eta^{t}\right)}{C\left(z^{t}\right)}=\frac{\zeta\left(z^{t}, \eta^{t}\right)^{-\frac{1}{\alpha}}}{h_{t}\left(z^{t}\right)}
$$

where $h_{t}\left(z^{t}\right)$ is defined as $h_{t}\left(z^{t}\right) \equiv \sum_{\eta^{t}} \zeta\left(z^{t}, \eta^{t}\right)^{-\frac{1}{\alpha}} \pi\left(\eta^{t}\right)$. In addition, by plugging the consumption sharing rule back into to the first-order condition with respect to consumption, equation (7), we obtain the price of the home consumption basket at state $z^{t}$ :

$$
P\left(z^{t}\right)=\beta^{t} C\left(z^{t}\right)^{-\alpha} h_{t}\left(z^{t}\right)^{\alpha} .
$$


Therefore, the stochastic discount factor is given by the Breeden-Lucas stochastic discount factor with a multiplicative adjustment:

$$
Q_{t+1}\left(z^{t+1} \mid z^{t}\right) \equiv \frac{P\left(z^{t+1}\right)}{P\left(z^{t}\right)}=\beta\left(\frac{C\left(z^{t+1}\right)}{C\left(z^{t}\right)}\right)^{-\alpha}\left(\frac{h_{t+1}\left(z^{t+1}\right)}{h_{t}\left(z^{t}\right)}\right)^{\alpha} .
$$

\section{A.2 PROOF OF LEMMA 1}

Given that our assumed growth rate of output is $g_{t+1}=\bar{g} e^{(\rho-1) m_{t}+\varepsilon_{t+1}}$ the one-period-ahead pricing kernel is $M_{t, t+1}=\beta \bar{g}^{-\alpha} e^{-\alpha(\rho-1) m_{t}} e^{-\alpha \varepsilon_{t+1}}$. The price of a one-period bond is therefore

$$
P_{t}^{1}=E_{t} M_{t, t+1}=\beta \bar{g}^{-\alpha} e^{-\alpha(\rho-1) m_{t}} e^{\alpha^{2} \frac{\sigma_{\varepsilon}^{2}}{2}},
$$

which is a function of the current deviation from trend $m_{t}$. The one-period yield is then

$$
r_{t}^{1}=-\ln P_{t}^{1}=-\ln \beta+\alpha \ln \bar{g}+\alpha(\rho-1) m_{t}-\frac{\alpha^{2} \sigma_{\varepsilon}^{2}}{2} .
$$

We derive the price of a $k$-period zero-coupon bond and its yields as follows:

$$
\begin{aligned}
P_{t}^{k}= & E_{t}\left[M_{t, t+k}\right]=E_{t}\left[\prod_{\tau+0}^{k-1} M_{t+\tau, t+\tau+1}\right] \\
& =\beta^{k} \bar{g}^{-k \alpha} e^{-\alpha(\rho-1)\left[\sum_{\tau=0}^{k=0} \rho^{\tau}\right] m_{t}\left[\sum_{t=0}^{k-1} \rho^{2 \tau}\right] \frac{\alpha^{2} \sigma_{\varepsilon}^{2}}{2}}, \\
r_{t}^{k} & =\frac{1}{k} \ln P_{t}^{k} \\
& =-\ln \beta+\alpha \ln g+\alpha(\rho-1) \frac{1}{k} \frac{1-\rho^{k}}{1-\rho} m^{t}-\frac{1-\rho^{2 k}}{1-\rho^{2}} \frac{\alpha^{2} \sigma_{\varepsilon}^{2}}{2} .
\end{aligned}
$$

The term premium at period $t$ for a $k$-period zero-coupon bond is

$$
r_{t}^{k}-r_{t}^{1}=\alpha(1-\rho)\left[1-\frac{1}{k} \frac{1-\rho^{k}}{1-\rho}\right] m^{t}+1\left[1-\frac{1}{k} \frac{1-\rho^{2 k}}{1-\rho^{2}}\right] \frac{\alpha^{2} \sigma_{\varepsilon}^{2}}{2},
$$

which is again a function of $m_{t}$. Taking the unconditional expectation of $r_{t}^{k}-r_{t}^{l}$ gives equation (6) because of $E\left(m_{t}\right)=0$.

Moreover, we want to show that the term premium is increasing with $k$, that is, for $\frac{\partial E\left[r_{t}^{k}-r_{t}^{1}\right]}{\partial k}>0$ for $k>1$. First, notice that $\rho^{2 k}\left(1-\ln \rho^{2 k}\right)<1$ because (i) $\lim _{\rho^{2 k} \rightarrow 1} \rho^{2 k}\left(1-\ln \rho^{2 k}\right)=1$ and (ii)

$$
\frac{\partial\left[\rho^{2 k}\left(1-\ln \rho^{2 k}\right)\right]}{\partial \rho^{2 k}}=-\ln \rho^{2 k}>0 \text { if } \rho^{2 k}<1 .
$$

Second, by using the fact that $\sum_{\tau=0}^{k-1} \rho^{\tau}=\frac{1-\rho^{2 k}}{1-\rho^{2}}$, the average term premium can be rewritten as 


$$
E\left[r_{t}^{k}-r_{t}^{1}\right]=\frac{\alpha^{2} \sigma_{\varepsilon}^{2}}{2}-\frac{\alpha^{2} \sigma_{\varepsilon}^{2}}{2\left(1-\rho^{2}\right)} \times \frac{1-\rho^{2 k}}{k}
$$

and hence the derivative of $E\left[r_{t}^{k}-r_{t}^{l}\right]$ with respect to $k$ is

$$
\begin{aligned}
& \frac{\partial E\left[r_{t}^{k}-r_{t}^{1}\right]}{\partial k}=\frac{\alpha^{2} \sigma_{\varepsilon}^{2}}{2\left(1-\rho^{2}\right)} \times \frac{1-\rho^{2 k}\left(1-\ln \rho^{2 k}\right)}{k^{2}} \\
& >0 \text { if } \rho<1 \text { and } k>1 .
\end{aligned}
$$

The last inequality uses the fact that $\rho^{2 k}\left(1-\ln \rho^{2 k}\right)<1$ if $\rho^{2 k}<1$.

\section{NOTES}

1 The standard equilibrium macroeconomic model refers to the classical representative agent complete-market model, such as the one in Mehra and Prescott (1985). See also Grkaynak and Wright (2012) for a review of issues related to term premia.

$\underline{2}$ In this article, the terms "household," "trader," and "investor" are used interchangeably.

$\underline{3}$ The statistics for the representative agent economy are reported in the "RA economy" column of Table 2.

\section{REFERENCES}

Abel, A.B. "Risk Premia and Term Premia in General Equilibrium." Journal of Monetary Economics, 1999, 43, pp. 3-33; https://doi.org/10.1016/S0304-3932(98)00039-7.

Alvarez, F. and Jermann, U. "Quantitative Asset Pricing Implications of Endogenous Solvency Constraints." Review of Financial Studies, 2001, 14, pp. 1117-52; https://doi.org/10.1093/rfs/14.4.1117.

Backus, D.K.; Gregory, A.W. and Zin, S.E. "Risk Premiums in the Term Structure: Evidence from Artificial Economies." Journal of Monetary Economics, 1989, 24(3), pp. 371-99; https://doi.org/10.1016/0304-3932(89)90027-5.

Bansal, R. and Shaliastovich I. "A Long-Run Risks Explanation of Predictability Puzzles in Bond and Currency Markets." Review of Financial Studies, 2013, 26(1), pp. 1-33; https://doi.org/10.1093/rfs/hhs108.

Bansal, R. and Yaron A. "Risks for the Long Run: A Potential Resolution of Asset Prizing Puzzles." Journal of Finance, 2004, 59, 1481-509; https://doi.org/10.1111/j.1540-6261.2004.00670.x.

Campbell, J.Y. "Bond and Stock Returns in a Simple Exchange Model." Quarterly Journal of Economics, 1986, 101, pp. 785-804; https://doi.org/10.2307/1884178.

Chien, Y.; Cole H. and Lustig H. "A Multiplier Approach to Understanding the Macro Implications of Household Finance." Review of Economic Studies, 2011, 78(1), pp. 199-234; https://doi.org/10.1093/restud/rdq008.

Christiano, L.J. and Eichenbaum M. “Unit Roots in Real GNP: Do We Know, and Do We Care?” Working Paper Series, Macroeconomic Issues 90-2, Federal Reserve Bank of Chicago, 1990.

den Haan, W.J. "The Term Structure of Interest Rates in Real And Monetary Economies." Journal of Economic Dynamics and Control, 1995, 19(5-7), pp. 909-40; https://doi.org/10.1016/0165-1889(94)00813-W.

Donaldson, J. B.; Johnsen, T. and Mehra, R. "On the Term Structure of Interest Rates." Journal of Economic Dynamics and Control, 1990, 14(3-4), pp. 571-96; https://doi.org/10.1016/0165-1889(90)90034-E.

Grkaynak, R.S. and Wright, J.H. "Macroeconomics and the Term Structure." Journal of Economic Literature, 2012, 50(2), pp. 331-67; https://doi.org/10.1257/jel.50.2.331.

Guiso, L. and Sodini, P. “Household Finance. An Emerging Field.” EIEF Working Paper, 2012. 


\section{Chien and Lee}

Mehra, R. and Prescott E.C. “The Equity Premium: A Puzzle.” Journal of Monetary Economics, 1995, 15(2), pp. 145-61; https://doi.org/10.1016/0304-3932(85)90061-3.

Mendoza, E.G.; Quadrini, V. and Rios-Rull, J.-V. "Financial Integration, Financial Development, and Global Imbalances." Journal of Political Economy, 2009, 117(3), pp. 371-416; https://doi.org/10.1086/599706.

Piazzesi, M. and Schneider, M. "Equilibrium Yield Curves," in NBER Macroeconomics Annual 2006. Volume 21. National Bureau of Economic Research, Inc., 2007, pp. 389-472.

Rudebusch, G.D. and Swanson, E.T. "The Bond Premium in a DSGE Model with Long-Run Real and Nominal Risks." American Economic Journal: Macroeconomics, 2012, 4(1), pp. 105-43; https://doi.org/10.1257/mac.4.1.105.

Storesletten, K.; Telmer, C.I. and Yaron, A. "Cyclical Dynamics in Idiosyncratic Labor Market Risk." Journal of Political Economy, 2004, 112(3), pp. 695-717; https://doi.org/10.1086/383105.

Ulrich, M. "Inflation Ambiguity and the Term Structure of U.S. Government Bonds." Journal of Monetary Economics, 2013, 60(2), pp. 295-309; https://doi.org/10.1016/j.jmoneco.2012.10.015.

Wachter, J. "A Consumption-Based Model of the Term Structure of Interest Rates." Journal of Financial Economics, 2006, 79, pp. 365-99; https://doi.org/10.1016/j.jineco.2005.02.004.

Wright, J.H. "Term Premia and Inflation Uncertainty: Empirical Evidence from an International Panel Dataset." American Economic Review, 2011, 101(4), pp. 1514-34; https://doi.org/10.1257/aer.101.4.1514. 